\title{
Changes in leisure time and occupational physical activity over 8 years: the Cornellà Health Interview Survey Follow-Up Study
}

\author{
C I Cornelio, ${ }^{1,2}$ M García, ${ }^{1}$ A Schiaffino, ${ }^{1,2} \mathrm{~J}$ M Borràs, ${ }^{1,3} \mathrm{~F}$ J Nieto, ${ }^{4}$ E Fernández, ${ }^{1,2}$ \\ for the CHIS.FU Study Group*
}

${ }^{1}$ Cancer Prevention and Control Unit, Institut Català d'Oncologia, IDIBELL, L'Hospitalet, Barcelona, Spain; ${ }^{2}$ Department of Experimental and Health Sciences, Universitat Pompeu

Fabra, Barcelona, Spain;

${ }^{3}$ Department of Clinical

Sciences, IDIBELL, Universitat de Barcelona, Spain; ${ }^{4}$ Department of Population Health Sciences, School of Medicine and Public Health, University of Wisconsin, Madison, WI, USA

Correspondence to: Esteve Fernandez, MD, PhD, Cancer Prevention and Control Unit, Institut Català d'Oncologia, Av Gran Via s/n, Km 2.7, 08907 L'Hospitalet, Barcelona, Spain; efernandez@ico.scs.es

*The CHIS.FU Study Group: Esteve Fernandez (principal investigator), Anna Schiaffino and Montse Garcia (study coordinators), and Mercè Martí, Esteve Saltó, Glòria Pérez, Mercè Peris, Carme Borrell, F Javier Nieto, and Josep Maria Borràs (associate researchers)

\section{ABSTRACT}

Aim: To describe changes in leisure time and occupational physical activity status in an urban Mediterranean population-based cohort, and to evaluate sociodemographic, health-related and lifestyle correlates of such changes.

Methods: Data for this study come from the Cornellà Health Interview Survey Follow-Up Study, a prospective cohort study of a representative sample $(n=2500)$ of the population. Participants in the analysis reported here include 1246 subjects (567 men and 679 women) who had complete data on physical activity at the 1994 baseline survey and at the 2002 follow-up. We fitted Breslow-Cox regression models to assess the association between correlates of interest and changes in physical activity.

Results: Regarding leisure time physical activity, $61.6 \%$ of cohort members with "sedentary" habits in 1994 changed their status to "light/moderate" physical activity in 2002, and 70\% who had "light/moderate" habits in 1994 did not change their activity level. Regarding occupational physical activity, $74.4 \%$ of cohort members who were "active" did not change their level of activity, and $64.3 \%$ of participants with "sedentary" habits in 1994 changed to "active" occupational physical activity. No clear correlates of change in physical activity were identified in multivariate analyses.

Conclusion: While changes in physical activity are evident in this population-based cohort, no clear determinants of such changes were recognised. Further longitudinal studies including other potential individual and contextual determinants are needed to better understand determinants of changes in physical activity at the population level.

Regular physical activity has been linked with positive effects on health and wellbeing and its association with reduced all-cause mortality is well established. ${ }^{12}$ Not surprisingly, increasing population physical activity levels has been chosen as one of the leading health goals for the year 2010. ${ }^{3}$ Although most of the recommendations hinge on individuals' behaviour and focus primarily on activities based on clinical settings, the importance of population-level determinants is also recognised. ${ }^{4}$ Therefore, the role of community-based intervention to promote healthy changes in physical activity is of importance in a global strategy for health promotion and prevention.

Change in physical activity behaviour and its correlation with other health behaviours has been used as a tool to assess the effectiveness of health promotion strategies. ${ }^{5}$ However, the few studies conducted to date have been either cross-sectional analyses ${ }^{6}$ or limited to specific trial interventions. ${ }^{78}$ Prospective studies in representative population samples may be helpful to assess the community status of physical activity change and to evaluate variables linked to changes in physical activity that could guide better public health interventions. The present study is, therefore, aimed at describing changes in leisure time and occupational physical activity status in an urban Mediterranean population-based cohort, and to evaluate sociodemographic, health-related and lifestyle correlates of such changes.

\section{METHODS}

\section{Study subjects}

The Cornellà Health Interview Survey Follow-Up (CHIS.FU) Study is a prospective cohort of a representative sample $(\mathrm{n}=2500 ; 1263$ women and 1237 men) of the non-institutionalised population from Cornellà de Llobregat, a city located in the metropolitan area of Barcelona, Catalonia, Spain, with a total population of 85061 inhabitants. The cohort was established in 1994 with participants randomly selected from the general population and interviewed face-to-face in their home. In 2002 (8 years after the baseline interview), subjects were contacted and interviewed by telephone. Details on subject recruitment and procedures are described elsewhere. ${ }^{10}$ Briefly, 1608 subjects responded to the follow-up interview in 2002 (response rate of 64.3\%); 1438 participants were directly interviewed and in the remaining 170 follow-up information was obtained through proxy interview. There were 123 (4.9\%) refusals, $425(17.0 \%)$ of the cohort members had emigrated and 147 (5.9\%) had died. The remaining 197 (7.9\%) subjects could not be contacted. The present analysis is based on 1246 subjects (567 men and 679 women) who had complete data on physical activity both at baseline (1994) and at the followup interview (2002). Physical activity and other baseline sociodemographic and lifestyle characteristics were unrelated to attrition in this cohort. ${ }^{11}$

\section{Study variables}

Leisure time physical activity (LTPA) and occupational physical activity (OPA) in the previous 7 days were assessed using adapted questionnaires from the US Health Interview Survey and the Welsh Heart Health Study ${ }^{12-14}$; these instruments 
have been previously used in similar population surveys. ${ }^{15-17}$ LTPA was assessed with the following questions:

- During last week, how many times did you perform any light physical activity for at least 20 minutes (walking, light recreational activities, going upstairs)?

- During last week, how many times did you perform any moderate physical activity for at least 20 minutes (riding a bike, gym, running, tennis, swimming)?

- During last week, how many times did you perform any intense physical activity for at least 20 minutes (team sports, hockey, football, physical training)?

We then classified LTPA in 1994 and in 2002 into the following categories: sedentary: people who did not perform any activity; light/moderate: any number of times/week of light activity gathered from question 1 and up to two times/week of moderate or vigorous physical activity gathered from questions 2 and 3; and vigorous: more than two times/week any moderate or vigorous physical activity gathered from questions 2 and 3 .

OPA was assessed with the question: "Which of the following options best describes your main or usual activity?

- Inactive: sitting down most of the day

- Light: standing most of the day, with little movement or exertions of energy

- Moderate: walking, carrying some weight, frequent movement

- Intense: physical effort and heavy labour.

We then classified OPA in 1994 and in 2002 into two main categories: sedentary: subjects who answered options 1 or 2 and; and active: subjects who replied options 3 and 4 as daily activities.

To further characterise subjects' profile regarding LTPA and OPA changes at follow-up, we defined a "positive" change when an upper level of physical activity was reached in 2002 from a "sedentary" status in 1994. A "negative" LTPA change was identified when subjects changed from "light/moderate" to "sedentary" LTPA. A "negative" OPA change was identified when subjects changed from "active" OPA in 1994 to "sedentary" in 2002.

Other independent variables in these analyses included sociodemographic characteristics as measured in 1994: sex, age (15-24 years; 25-44 years; 45-64 years; $\geqslant 65$ years), maximum educational level attained (less than primary or primary studies; secondary or university studies) and social class categorised in terms of occupation. Social class was defined following the Spanish adaptation of the British Registrar General classification $^{18}$ : class I (directives of the public administration and managers of companies with 10 or more employees, professionals associated with advanced university degree); class II (managers of companies with fewer than 10 employees, professionals associated with initial university degree, technicians and support professionals, artists, sportsmen); class IIIa (administrative workers and support professionals in administrative and financial management, workers in personal and security services); class IIIb (self employed workers); class IIIc (supervisors of manual workers); class IVa (high skilled manual workers); class IVb (semiskilled manual workers); and class V (unskilled manual workers). For the analysis, we grouped these categories in three levels: class I-II, class III (IIIa + IIIb), and class $\mathrm{IV}-\mathrm{V}(\mathrm{IVa}+\mathrm{IVb}+\mathrm{V})$. We also used working status according to main activity (employed; unemployed; disabled or retired; student; housewife); lifestyle variables: smoking (never smokers; former smoker; current smokers-including occasional and daily smokers), alcohol consumption (non-drinkers and thirds of consumption in $\mathrm{g} /$ day according to the separate distribution in men and women) and health-related variables: number of chronic conditions $(0 ; 1$ and $\geqslant 2$ ); self perceived health (recoded into two categories as "suboptimal" if subjects declared themselves to have a "poor rather bad," "bad," or "very bad" health and as "optimal" if they declared themselves to have a "poor rather good," "good," or "very good" health) and body mass index (BMI) calculated as weight/height squared $\left(\mathrm{kg} / \mathrm{m}^{2}\right)$. "Obesity/overweight" was defined as BMI $\geqslant 25.0 \mathrm{~kg} / \mathrm{m}^{2}$; BMI between 18.5 and $24.9 \mathrm{~kg} / \mathrm{m}^{2}$ was considered "normal" weight.

In order to investigate the variables that were associated with changes in physical activity, we fitted Breslow-Cox regression models to calculate the hazard ratio (HR) of change in LTPA and OPA and corresponding 95\% confidence intervals (CI). ${ }^{19}$ The assumption of proportionality of hazards was verified using standard graphic and statistical methods. Separate analyses for men and women were conducted. All models were adjusted for age and, when necessary, for other potential confounders (that is, educational level).

\section{RESULTS}

Baseline characteristics (1994 survey) and at follow-up (2002 survey) of the 1246 cohort participants who had complete data on physical activity in 1994 and 2002 are shown in table 1. Not surprisingly, some changes in the distribution of certain lifestyle characteristics (that is, smoking and alcohol) and in physical activity levels between baseline and follow-up survey were observed.

\section{Leisure time physical activity (LTPA)}

The joint distribution of results according to LTPA levels in 1994 and 2002 (table 2) shows that $61.6 \%$ of cohort members with sedentary habits in 1994 had changed their status to light/ moderate LTPA in 2002 (25.6\% of the whole cohort). The change was similar in men (64.4\%) and women (59.9\%). Only $7.5 \%$ of the population moved from sedentary to vigorous LTPA, principally men. A similar percentage of subjects (10.2\%) changed their habits from light/moderate to vigorous. Most participants $(71.0 \%)$ reporting light/moderate levels of LTPA in 1994 did not change. The proportion of subjects who decreased their LTPA habits from light/moderate to sedentary was $18.8 \%$.

After controlling for age, women presented a non-significant lower risk of "positive" change in LTPA (HR $=0.9,95 \%$ CI: 0.7 to 1.1). In men, the likelihood of "positive" change increased with increasing age up to the age of 64. In contrast, an inverse association with age was observed in women: the frequency of change decreased to $34 \%$ in women over 64 ( $\mathrm{HR}=0.7,95 \% \mathrm{CI}$ : 0.4 to 1.2). None of the other factors analysed showed a significant association with positive change. A positive change in LTPA appeared to be more frequent in educated and occupationally active women but the difference was not statistically significant. With respect to LTPA "negative" change, women had greater (but not statistically significant) likelihood of decreasing LTPA level compared to men (HR $=1.3$, $95 \%$ CI: 0.9 to 1.9 ). Men aged $45-64$ were $60 \%$ less likely to experience a "negative" change in level of LTPA ( $\mathrm{HR}=0.4,95 \%$ CI: 0.2 to 0.8 ) when compared with younger men. Moreover, those with secondary or college education had a lower (but nonsignificant) probability of LTPA change ( $\mathrm{HR}=0.5,95 \% \mathrm{CI}: 0.2$ to 1.1$)$.

\section{Occupational physical activity (OPA)}

Of 745 cohort members with a sedentary level of OPA in 1994, $479(64.3 \%)$ were active in 2002 (table 3). On the other hand, of 
Table 1 Baseline (1994 survey) and follow-up (2002 survey) characteristics of 1246 cohort members who had complete information

\begin{tabular}{|c|c|c|}
\hline & 1994 & 2002 \\
\hline Characteristics & No $(\%)$ & No $(\%)$ \\
\hline \multicolumn{3}{|l|}{ Sex } \\
\hline Male & $567(45.5)$ & $567(45.5)$ \\
\hline Female & $679(54.5)$ & $679(54.5)$ \\
\hline \multicolumn{3}{|l|}{ Age (years) } \\
\hline $15-24$ & $337(19.0)$ & $37(3.0)$ \\
\hline $25-44$ & $370(29.7)$ & 415 (33.3) \\
\hline $45-64$ & 497 (39.9) & 468 (37.6) \\
\hline$\geqslant 65$ & $142(11.4)$ & $326(26.1)$ \\
\hline \multicolumn{3}{|l|}{ Education* } \\
\hline Less than primary & $213(17.1)$ & $324(26.1)$ \\
\hline Primary & $720(57.8)$ & $596(48.0)$ \\
\hline Secondary and university & $312(25.0)$ & $321(25.9)$ \\
\hline \multicolumn{3}{|l|}{ Social class* } \\
\hline I and II & $63(5.2)$ & $99(8.2)$ \\
\hline III & $191(15.6)$ & $217(18.0)$ \\
\hline IV and V & 968 (79.2) & $929(73.8)$ \\
\hline \multicolumn{3}{|l|}{ Occupational status } \\
\hline Employed & $471(37.9)$ & $607(48.7)$ \\
\hline Unemployed & $146(11.7)$ & $61(4.9)$ \\
\hline Disabled/retired & $141(11.3)$ & $317(25.4)$ \\
\hline Housewives & $335(27.0)$ & $230(18.5)$ \\
\hline Students & $153(12.2)$ & $31(2.5)$ \\
\hline \multicolumn{3}{|l|}{ Smoking habit } \\
\hline Never smokers & $778(62.4)$ & $689(55.4)$ \\
\hline Former smokers & $117(9.4)$ & 247 (19.8) \\
\hline Current smokers & $351(28.2)$ & 309 (24.8) \\
\hline \multicolumn{3}{|l|}{ Alcohol consumption ${ }^{*} \dagger$} \\
\hline Non-drinkers & $662(53.2)$ & $618(49.5)$ \\
\hline 1st third & $205(16.5)$ & $205(16.5)$ \\
\hline 2nd third & $167(13.4)$ & $202(16.5)$ \\
\hline 3rd third & $210(16.9)$ & $217(17.5)$ \\
\hline \multicolumn{3}{|l|}{ Leisure time physical activity } \\
\hline Sedentary & $518(41.6)$ & $292(23.4)$ \\
\hline Light/moderate & $599(48.0)$ & $798(64.0)$ \\
\hline Vigorous & $129(10.4)$ & $156(12.5)$ \\
\hline \multicolumn{3}{|l|}{ Occupational physical activity* } \\
\hline Sedentary & $751(60.5)$ & $390(31.7)$ \\
\hline Active & $491(39.5)$ & $839(68.3)$ \\
\hline \multicolumn{3}{|l|}{ Health-related } \\
\hline \multicolumn{3}{|l|}{ Self perceived health } \\
\hline Optimal & $1046(83.9)$ & 1044 (84.0) \\
\hline Suboptimal & $200(16.1)$ & $200(16.0)$ \\
\hline \multicolumn{3}{|l|}{ Number of chronic conditions } \\
\hline 0 & $473(38.0)$ & $278(23.0)$ \\
\hline 1 & $290(23.2)$ & $291(24.0)$ \\
\hline$\geqslant 2$ & $483(38.8)$ & $640(53.0)$ \\
\hline \multicolumn{3}{|l|}{ Body mass index* } \\
\hline Normal $\left(18.5 \mathrm{~kg} / \mathrm{m}^{2}-24.9 \mathrm{~kg} / \mathrm{m}^{2}\right)$ & $583(50.2)$ & $492(43.5)$ \\
\hline Overweight/obese $\left(\geqslant 25.0 \mathrm{~kg} / \mathrm{m}^{2}\right)$ & $579(49.8)$ & $638(53.5)$ \\
\hline
\end{tabular}

*The sum does not up the total because of some missing values. $\dagger$ Tertiles in men: $8 \mathrm{~g} /$ day and $22.4 \mathrm{~g} /$ day; tertiles in women: $1.6 \mathrm{~g} /$ day and $6.3 \mathrm{~g} /$ day.

480 active people in 1994, 357 (74.4\%) continued to be active in 2002. The percentage of active subjects who changed their status to a sedentary level of OPA was $25.6 \%$ in 2002 . The change from sedentary to active level of OPA was similar in men (63.9\%) and women (64.6\%). Remaining active in 2002 was also similarly frequent in men and women $(78.8 \%$ and $76.3 \%$, respectively).

In men, no pattern of association between age and the likelihood of "positive" change in OPA was observed. The frequency of a positive change in OPA in women increased with age (up to 65 years old). Women aged $45-64$ were twice as likely to increase their level of OPA compared to the youngest (HR 2.0 $95 \%$ CI 1.4 to 3.0). More educated women (secondary or college education) were less likely to show a positive change in OPA level after controlling for age (adjusted HR 0.8, 95\% CI 0.6 to 1.1). A "positive" change in OPA was less likely in both men and women of higher social class. In women, the frequency of "positive" change was related to the type of occupation, with housewives having a HR of $1.3(95 \% \mathrm{CI} 0.7$ to 2.2 ) compared to unemployed women In women, self perceived health was related to change in level of OPA: women who declared their health as "suboptimal" had a lower statistically non-significant probability of change ( $\mathrm{HR}=0.895 \% \mathrm{CI}$ : 0.6 to 1.2 ).

Men were less likely to have a "negative" change in OPA and showed a slightly inverse non-significant trend of decreasing risk with increasing age. A significant pattern was observed in women up to age 65 . Women aged $45-64$ had nearly $70 \%$ lower frequency of "negative" change in level of OPA when compared to younger women. A higher level of education attained was associated with a non-significant higher frequency of negative change in OPA both in men and women (HR $=1.5 ; 95 \%$ CI: 0.9 to 2.8 , and $\mathrm{HR}=1.8 ; 95 \% \mathrm{CI}: 0.8$ to 3.4 , respectively). This estimate was attenuated in men after adjustment for confounding variables. In women, multivariate analysis showed that being employed was associated with about $50 \%$ decrease in the frequency of a negative change when comparing with being unemployed (HR $=0.5,95 \% \mathrm{CI}: 0.3$ to 0.9 ) and confirmed that women who were more educated ( $\mathrm{HR}=2.0,95 \% \mathrm{CI}$ : 1.0 to 4.0 ) and older than 64 ( $\mathrm{HR}=3.0,95 \% \mathrm{CI}: 1.3$ to 6.8) had higher frequency of "negative" change in the level of OPA.

\section{DISCUSSION}

We found that among our study participants, $61.6 \%$ of those reporting sedentary LTPA habits and $64.3 \%$ reporting sedentary OPA at baseline changed to more active levels 8 years later. These changes are consistent with reported trends of increasing LTPA in Mediterranean populations, despite the fact that those populations have a high prevalence of obesity. ${ }^{20}{ }^{21}$

Even though we could not identify clear correlates of changes in either LTPA or OPA in this community-based study, they appear to be more closely associated with sociodemographic factors than with other health conditions, related behaviours or lifestyle. Although some studies ${ }^{22-24}$ have linked the former factors with the likelihood of change of physical activity, many others have not. ${ }^{25}{ }^{26}$ The lack of a statistically significant association between factors such as smoking habits and LTPA or self perceived health and OPA are possibly affected by the relatively small sample size of the cohort. It is important to keep in mind, however, that we only explored associations between change in physical activity in association with baseline levels of these risk factors (that is, smoking, alcohol consumption, BMI, etc), thus assuming that those factors remained unchanged during follow-up. Changes in these risk factors may affect changes in physical activity and, thus, this is a possible limitation of the study. Although we know that changes have occurred (table 1), we can't determine at which point in the follow-up these changes occurred, and hence we are not able to properly adjust for them in the analysis. However, our findings are in agreement with previously published results reporting no association or weak associations between changes in LTPA status and tobacco, alcohol consumption or obesity. ${ }^{27}$ Our study focused mainly on the "first step of change," from sedentary to light/moderate LTPA, since sedentary subjects are those most 
Table 2 Changes in leisure time physical activity between 1994 and 2002 by sex

\begin{tabular}{|c|c|c|c|c|}
\hline \multirow[b]{3}{*}{ Leisure time physical activity in 1994} & \multirow[b]{3}{*}{ No (\%) } & \multicolumn{3}{|c|}{ Leisure time physical activity in 2002} \\
\hline & & Sedentary & Light/moderate & Vigorous \\
\hline & & No (\%) & No (\%) & No (\%) \\
\hline Sedentary & $518(100)$ & $160(30.9)$ & $319(61.6)$ & $39(7.5)$ \\
\hline Light/moderate & $599(100)$ & $113(18.8)$ & $425(71.0)$ & $61(10.2)$ \\
\hline Vigorous & $129(100)$ & $19(14.7)$ & $54(41.9)$ & $56(43.4)$ \\
\hline Light/moderate & $290(100)$ & $46(15.9)$ & $214(73.8)$ & $30(10.3)$ \\
\hline Vigorous & $83(100)$ & $9(10.8)$ & $32(38.6)$ & $42(50.6)$ \\
\hline \multicolumn{5}{|l|}{ Women } \\
\hline Sedentary & $324(100)$ & $109(33.6)$ & $194(59.9)$ & $21(6.5)$ \\
\hline Light/moderate & $309(100)$ & 67 (21.7) & $211(68.3)$ & $31(10.0)$ \\
\hline Vigorous & $46(100)$ & $10(21.7)$ & $22(47.8)$ & $14(30.4)$ \\
\hline
\end{tabular}

critically needing some increase in physical activity. Demographic factors, such as age and sex, were related to physical activity changes. Gender differences in reported LTPA levels were consistent with previous reports ${ }^{28}$ and the association with age varied according to gender. Positive changes in LTPA were more likely in men than in women. Men reaching their 40s were more stable in their habits. Thus, targeting behavioural interventions to young men may have greater impact from a public health perspective. In this cohort, women were less likely to modify their physical activity habits, regardless of age.

Some authors have argued that decreasing OPA is one of the factors implicated in the steadily increasing prevalence of obesity in the developed world. ${ }^{29}{ }^{30}$ In such societies, an increasing reliance on technology has considerably reduced work-related physical activity and the energy expenditure required for daily living. The circumstances in specific community settings such as ours with a unique social or cultural environment and economic organisation may lead to different relations between these social phenomena, however. The results of this study show that there were positive changes in OPA that could be attributable in part to changes in the overall pattern of occupation of the cohort: the proportion of employed people increased between 1994 (37.9\%) and 2002 (48.7\%) (table 1); it is conceivable that those newly employed were in occupations with higher demands of OPA. Although an association of physical activity and social class has been reported by several authors, ${ }^{31-33}$ the relative homogeneity of social class in our cohort (nearly $80 \%$ of the population belong to social class categories IV and V) limited our ability to explore this issue.
Nevertheless, we did observe some degree of association between education and changing physical activity habits, especially in women. Educated and occupationally active women were more likely to increase their LTPA; furthermore employed women had greater tendency to be active in OPA terms. On the other hand, educated and older women had a greater probability to change to sedentary occupation-related physical activity. Therefore, this reveals some association between social class, education and occupation, as previously described in the literature..$^{34} 35$

Physical and social environment have been linked with increased physical activity. ${ }^{36}$ Community interventions ${ }^{6}{ }^{67}$ to reduce sedentariness and to promote healthy habits have been proposed as primary health promotion activities. In addition, physical activity is ranked as a leading health indicator for future objectives of health improvement. ${ }^{38}$ Several campaigns promoted walking and local community-sponsored wellness initiatives to promote exercise and to reduce cholesterol levels were developed in Cornellà de Llobregat during the late 1990s. ${ }^{39}$ Whereas our objective did not focus on measuring the effectiveness of such activities, their impact could partially explain the magnitude of the observed changes in this population. Our design lacks repeated measures of physical activity at regular points of time that would have helped in evaluating a potential progressive increase in physical activity. Complementary information, not only at the individual level but at contextual level (that is, number of fitness facilities in neighbourhoods), should also be included in new studies aimed at assessing changes in physical activity. Available evidence suggests the benefits of a moderate amount of regular walking

Table 3 Changes in occupationl physical activity between 1994 and 2002 by sex

\begin{tabular}{|c|c|c|c|}
\hline \multirow[b]{3}{*}{ Occupational physical activity in 1994} & \multirow[b]{3}{*}{ No $(\%)$} & \multicolumn{2}{|c|}{ Occupational physical activity in 2002} \\
\hline & & Sedentary & Active \\
\hline & & No $(\%)$ & No (\%) \\
\hline \multicolumn{4}{|c|}{ All } \\
\hline Sedentary & $745(100)$ & $266(35.7)$ & $479(64.3)$ \\
\hline Active & $480(100)$ & $123(25.6)$ & $357(74.4)$ \\
\hline \multicolumn{4}{|l|}{ Men } \\
\hline Sedentary & $349(100)$ & $126(36.1)$ & $223(63.9)$ \\
\hline Active & $202(100)$ & $57(28.2)$ & $145(78.8)$ \\
\hline \multicolumn{4}{|l|}{ Women } \\
\hline Sedentary & $396(100)$ & $140(35.4)$ & $256(64.6)$ \\
\hline Active & $278(100)$ & $66(23.7)$ & $212(76.3)$ \\
\hline
\end{tabular}




\section{What is already known on this topic}

While changes in physical activity behaviour can be used as a tool to assess effectiveness of health-promotion strategies, most studies have been cross-sectional in nature or have evaluated the effect of specific trial interventions.

\section{What this paper adds}

- After 8 years of follow-up, there are clear positive changes in the level of leisure time physical activity and occupational physical activity in this cohort

- Except for gender and education, no clear correlates of the changes in physical activity have been identified.

\section{Policy implications}

Changes in the levels of physical activity at the population level can be achieved and should be monitored.

in improving wellbeing and cardiovascular fitness, while being easier to maintain than more demanding physical activity levels that have been recommended by international organisations. ${ }^{40}$ The campaigns in Cornellà de Llobregat were noticeable in positive effects on the exercise intention and walking behaviours of the cohort members: more than $50 \%$ of subjects who changed to sedentary and light/moderate physical activity declared walking as the preferred daily activity (data not shown).

One potential limitation of our study could be some degree of information bias because of different ways of administering the questionnaire: the baseline interview was face-to-face at the participant's home while the follow-up questionnaire was administered by telephone. ${ }^{41}$ Face-to-face and telephone interviews have been shown to have high levels of agreement in a similar setting. ${ }^{42}$ The questions used were the same, and interviewers were similarly trained. However, some degree of non-differential misclassification is possible and, hence, some bias towards the null hypothesis cannot be ruled out.

Among the strengths of this study, its population-based, longitudinal and prospective design has permitted us to evaluate the actual change in physical activity patterns in a sample of the adult population. Moreover, we want to stress the high participation rates in the study. Ninety-two per cent of the Cornellà Health Interview Survey Follow-Up study members were effectively traced, and the response rate at follow-up was $64.2 \%{ }^{9}$

In addition, to our knowledge, this is the first study that evaluates changes and correlates in physical activity levels in a Mediterranean population-based cohort with active follow-up. The results presented here attempt to show how a community has changed habits in the last decade. These correlates (sociodemographic, health conditions and lifestyles) should not be represented as unchanging factors, but factors with close interdependence, and also with changing patterns across time. Unfortunately, our data do not allow us to adjust for changes in these factors, since we do not know exactly when the observed changes occurred. This is an aspect that future studies might consider addressing.
In conclusion, while some changes in physical activity are evident within this Mediterranean population, no clear correlates of such changes were identified except for sex, age and education. Further longitudinal analysis exploring other possible individual and contextual factors (for example, health promotion campaigns, availability of fitness and sports facilities, neighbourhood levels of physical activity, etc) are needed to better understand the determinants of changes observed.

Funding: This study was funded by Fondo de Investigación Sanitaria (PI02/0261), Instituto de Salud Carlos III (Network for Research in Cancer, RTICC, C03/10 and RD/ 06/0020/0089) and Government of Catalonia (2005SGR00646). CIC was supported by the Programme Alßan, the European Union Programme of High Level Scholarships for Latin America, scholarship No E04D045892AR.

\section{Competing interests: None.}

Contributors: EF, AS, MG and JMB designed the study protocol. AS and MG coordinated the follow-up data collection. EF and CIC designed the study on changes in physical activity to which all the authors made contributions. CIC checked all the information referring to physical activity. CIC, MG and EF defined the analysis strategy, $\mathrm{CIC}$ performed the statistical analysis, and all the authors contributed to the interpretation of the results. CIC wrote the first draft of the manuscript to which all the authors made contributions. EF is the guarantor of the paper.

\section{REFERENCES}

1. Leon AS, Connett J, Jacobs DR, et al. Leisure-time physical activity levels and risk of coronary heart disease risk and death: the Multiple Risk Factor Intervention Trial. JAMA 1987;258:2388-95.

2. Paffenbarger $\mathbf{R}$, Kampert J, Lee IM, et al. Changes in physical activity and other life way patterns influencing longevity. Med Sci Sports Exerc 1994;26: 857-65.

3. US Department of Health and Human Services. Healthy people 2010. Conference edition. Washington, DC: Departmen of Health and Human Services, 2000.

4. Jenkins CD. Principles of community health intervention. In: Jenkins CD, ed. Building better health. A handbook of behavioral change. Washington DC: PAHO, 2003.

5. Kahn E, Ramsey L, Brownson R, et al. The effectiveness of interventions to increase physical activity. Am J Prev Med 2002;22 (4suppl):72-107.

6. Galan I, Rodriguez-Artalejo F, Tobías A, et al. Clustering of behavioural risk factors and their association with subjective health. Gac Sanit 2005;19:370-80.

7. Young DR, Haskell WL, Taylor CB. Effect of community health education on physical activity knowledge, attitudes, and behaviour. The Stanford Five-City project. Am J Epidemiol 1996;144:264-74.

8. McTiernan A, Schwartz R, Potter J, et al. Exercise clinical trials in cancer prevention research: a call to action. Cancer Epidemiol Biomarkers Prev 1999;8:201-7.

9. Garcia M, Schiaffino A, Fernández E, et al. The Cornellà Health Interview Survey Follow-up (CHIS.FU) Study: design, methods, and response rate. BCM Public Health 2003;3:12.

10. Garcia M, Fernandez E, Schiaffino A, et al. Smoking reduction in a population-based cohort. Prev Med 2005:40:679-84.

11. Garcia M, Fernandez E, Schiaffino A, et al. Attrition in a population-based cohort eight years after baseline interview: The Cornella Health Interview Survey Follow-up (CHIS.FU) Study. Ann Epidemiol 2005;15:98-104.

12. Pereira MA, FitzerGerald SJ, Gregg EW, et al. A collection of physical activity questionnaires for health-related research. Med Sci Sports Exerc 1997;29 (6 Suppl):S1-S205.

13. Health Promotion Authority for Wales. Welsh heart health survey, 1985. Cardiff: Heartbeat Wales Technical Reports, 1989.

14. Weiss TW, Slater CH, Green LW, et al. The validity of single-item, self-assessment questions as measures of adult physical activity. J Clin Epidemiol 1990;43:1123-9.

15. Dominguez-Berjon F, Borrell $C$, Nebot $M$, et al. Physical activity assessment in population surveys: can it really be simplified? Int J Epidemiol 1999;28:53-7.

16. Dominguez-Berjon MF, Borrell C, Nebot M, et al. La actividad fisica de ocio y su asociacion con variables sociodemograficas y otros comportamientos relacionados con la salud. Gac Sanit 1998;12:100-9.

17. Dominguez-Berjon MF, Borrell $\mathrm{C}$, Nebot M, et al. Actividad fisica habitual de la poblacion residente en la ciudad de Barcelona. Gac Sanit 1998;12:110-7.

18. Domingo A, Marcos J. Propuesta de un indicador de la "clase social" basado en la ocupación. Gac Sanit 1989;3:320-6.

19. Breslow N. Covariance analysis of censored survival data. Biometrics 1974;30:8999.

20. Rodriguez Artalejo F, Lopez Garcia E, Gutierrez-Fisac JL. Changes in the prevalence of overweight and obesity and their risk factors in Spain, 1987-1997. Prev Med 2002;34:72-81.

21. Gutierrez-Fisac JL, Regidor E, Lopez Garcia E, et al. The obesity epidemic and related factors: the case of Spain. Cad Saude Publica 2003;19 (Suppl 1):S101-S110.

22. Weinsier R, Hunter G, Heini A, et al. The aetiology of obesity: relative contribution of metabolic factors, diet and physical activity. Am J Med 1998;105:145-50.

23. Pols M, Peeter P, Twisk J, et al. Physical activity and cardiovascular disease profile in women. Am J Epidemiol 1997;146:322-8. 
24. Guallar-Castillon P, Santa Olalla Peralta P, Banegas JR, et al. Actividad fñisica y calidad de vida de la población adulta mayor en España. Med Clin (Barc) 2004;123:606-10.

25. Rainwater DL, Mitchell BD, Comuzzie AG, et al. Association among 5-year changes in weight, physical activity, and cardiovascular disease risk factors in Mexican Americans. Am J Epidemiol 2000;152:974-82.

26. Sternfeld B, Sidney S, Jacobs D Jr, et al. Seven-year changes in physical fitness, physical activity, and lipid profile in the CARDIA Study. Ann Epidemiol 1999:9:25-33.

27. Schroder H, Elosua R, Marrugat J, et al. The relationship of physical activity with dietary cancer-protective nutrients and cancer-related biological and life style factors. Eur J Cancer Prev 2003;12:339-46.

28. Merritt RK, Caspersen C. Trend in physical activity patterns in young adults: the behaviours risk factor surveillance system, 1986-1990. Med Sci Sports Exerc 1992:24:526-30

29. Hill J, Melanson E. Overview of the determinants of overweight and obesity: current evidence and research issues. Med Sci Sports Exerc 1999;31 (11 Suppl):S515-s521.

30. Jebb SA, Moore MS. Contribution of a sedentary lifestyle and inactivity to the etiology of overweight and obesity: current evidence and research issues. Med Sci Sports Exerc 1999;31 (11 Suppl):S534-S541.

31. Ford ES, Merritt RK, Heath GW, et al. Physical activity behaviours in lower and higher socio-economic status populations. Am J Epidemiol 1991;133:1246-56.

32. Schroder H, Rohlfs I, Schmelz EM, et al. Relationship of socioeconomic status with cardiovascular risk factors and lifestyle in a Mediterranean population. Eur J Nutr 2004; $43: 77-8$.
33. Borrell C, Dominguez- Berjón F, Pasarín MI, et al. Social inequalities in health related behaviors in Barcelona. J Epidemiol Community Health 2000;54:24-30.

34. Droomers M, Schrijvers CT, Mackenbach JP. Educational level and decreases in leisure time physical activity: predictors from the longitudinal GLOBE study. J Epidemiol Community Health 2001;55:562-8.

35. Schmitz K, French S, Jeffery R. Correlates of changes in leisure time physical activity over 2 years: The Healthy Worker Project. Prev Med 1997;26:570-9.

36. Hill J0, Peters JC. Environmental contributions to the obesity epidemic. Science 1998;280:1371-4

37. Wimbush $\mathbf{E}$, MacGregor A, Fraser $\mathrm{E}$. Impacts of a national mass media camping on walking in Scotland. Health Prom Int 1998;13:45-54.

38. Roure E, Vallbona C, Tresserras R, et al. Actividad física. Evaluación de los objetivos del Plan de Salud de Cataluña para el año 2000. Med Clin (Barc) 2003;121 (suppl 1):51-5.

39. World Health Organization. Ageing and life course. The global embrace 2000. Highlights from Europe. Geneva: WHO, 2000 Available at: www.who.int/docstore/ globalmovement/embrace2000 [accessed 30 May, 2006].

40. Macera CA, Ham SA, Yore MM, et al. Prevalence of physical activity in the United States: Behavioral Risk Factor Surveillance System, 2001. Prev Chronic Dis 2005;2:A17. Epub 15 Mar 2005.

41. Garcia M, Fernandez E, Schiaffino A, et al. Survey Follow-up Study Group. Phone tracking in a follow-up study. Soz Praventivmed 2005;50:63-6.

42. Galán I, Rodriguez-Artalejo F, Zorrilla B. Comparación entre encuestas telefónicas y encuestas "cara a cara" domiciliarias en la estimación de hábitos de salud y prácticas preventivas. Gac Sanit 2004;18:440-50

No busy professional has time to browse through all pertinent journals to find relevant articles, but with Related Collections you no longer have to. Follow the "Related Collections" link from any article and use the "Show Collections from other Journals" to expand your search across all BMJ Journals. Or simply follow the "Browse by topic" link on the home page. By setting up your own collections and receiving email alerts every time an article is added to your chosen area, you can build up your own significant body of knowledge. 